\title{
Workforce active ageing case study in a Romanian manufacturing company
}

\author{
Roland Iosif Moraru, ${ }^{1,}$, Lucian-Ionel Cioca $^{2}$, and Gabriel Bujor Babut ${ }^{1}$ \\ ${ }^{1}$ University of Petroşani, Faculty of Mines, 332006 Petroşani, Romania \\ ${ }^{2}$ University "Lucian Blaga" of Sibiu, Faculty of Engineering, 550025 Sibiu, Romania
}

\begin{abstract}
Ageing workforce is a major trend that characterizes the demographic evolution of Europe, which generally affects the society, but also the organizations from economic and social point of view. Employers should change their negative perceptions of ageing workforce, whereas the changes that occur along with ageing are unable to influence the efficiency of work, assuming that a suitable strategy implemented to prevent and manage potential problems. The paper includes European and national statistics on the issue, a case study analysing the workforce ageing management in a Romanian manufacturing company, which has succeeded in achieving the active ageing target, and - on this basis - several good practice recommendations given on the approach employers should have on the workforce with regard to age.
\end{abstract}

\section{Introduction}

Worldwide, lately was observed a trend of an aging workforce, on the one hand due to increasing life expectancy, but also due to the increase in retirement age [1-2]. Regardless of workers age, the employer has the same responsibilities when it comes to health and safety [3-4]. Meanwhile, employers when hiring in companies cannot invoke the age issue. Each age has advantages regarding the conduct of professional activity. Thus, elder employees have a wide range of skills; have rich experience gained during their careers and extensive knowledge about the operations, which they perform. Younger workers are bringing new life and a fresh spirit in the activities they are involved in; they are very often innovators, have a strong desire for affirmation and have a greater capacity to work. From the proper mixture of the two types of employees can benefit the employer, both in terms of workload and of quality of provided products or services.

\section{Statistics at European and national level, by age}

In 2014, the employment rate of labor force in the European Union for people aged between 15 and 64 years, as measured under the EU labor force survey, was $64.9 \%$ (figure 1). The employment rate of older workers (aged 55 to 64 years) continued to grow fast despite the

" Corresponding author: roland moraru@yahoo.com 
financial and economic crisis that manifested itself in the Member States of the European Union. In the European Union, the employment rate of older workers reached 51.8\% in 2014 (figure 2); this rate has increased every year since 2002 to the present [5].

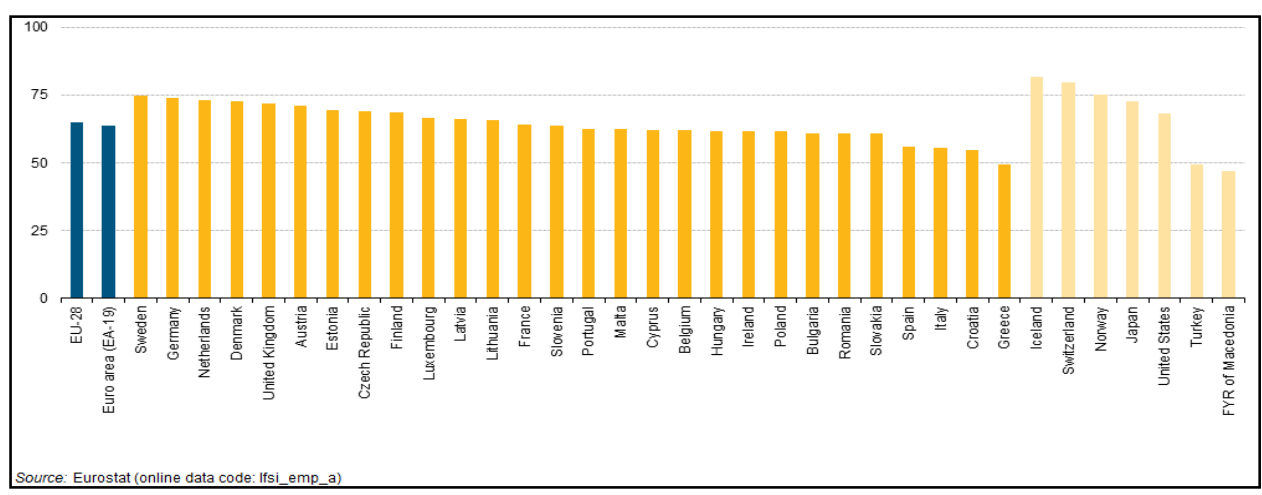

Fig. 1. Employment rate in EU, age group 15 - 64, 2014 [5]

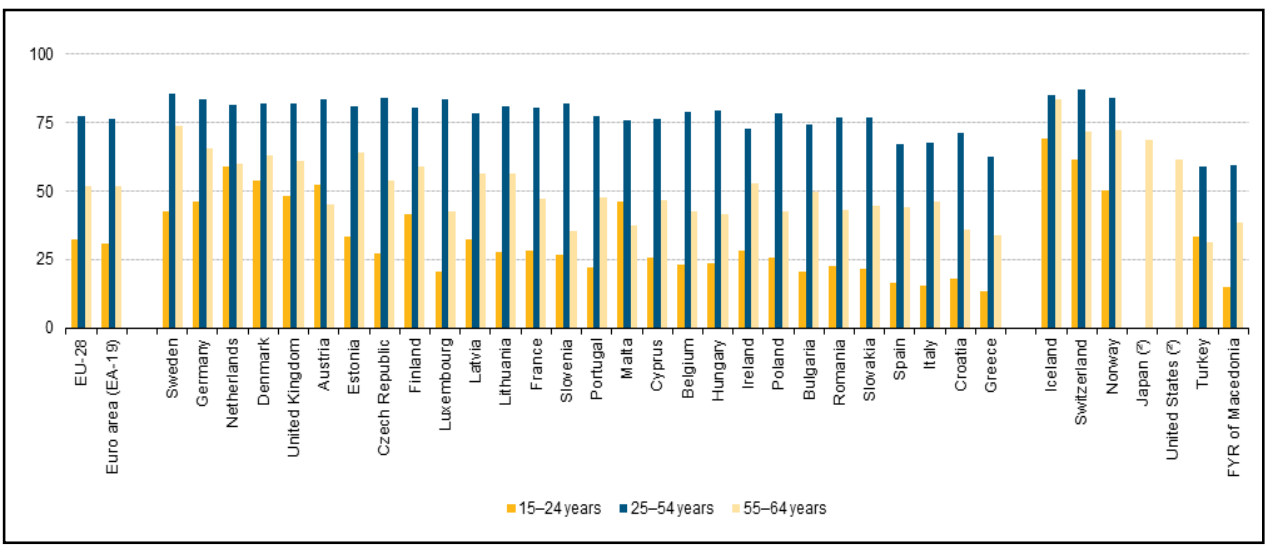

Fig. 2. Employment rate in EU, by age groups, 2014 [5]

In 2015, in eleven EU Member States the employment rate for senior workers was between 50\% and 66\%, while the highest rate recorded in Sweden $(74 \%)$ [6, 7, 9]. Employment statistics are at the heart of many EU policies. In March 2010, the European Commission launched the Europe 2020 strategy for smart, sustainable and inclusive growth; the European Council formally adopted it in June 2010 [9]. The European Council agreed on five main objectives, the first being to increase the employment rate for women and men aged from 20 to 64 years up to $75 \%$ in 2020 [10].

Population aging effects were also felt in Romania, being reported the phenomena of decrease of young workers employment, continuing the high levels of the active adult population and increase their number of elderly in the labor market. According to data from the National Institute of Statistics, in 2015 the Romania's active population was 9.159 thousand people, decreasing by 84000 people related to 2014 [11].

Those with medium level of education (57.6\%), by males $(57.2 \%)$ and those living in rural areas $(54.7 \%)$ held the largest share of total active population. Among the active population, $96.7 \%$ were in the age group (15-64 years). Young people accounted for $7.5 \%$ of the active population, more than half $(62.3 \%)$ residing in rural areas. The activity rate of the population aged 20-64 years was $70.8 \%$. In 2015, the employed population comprised 8.535 thousand people; of these, the people able to work (15-64 years) represented 96.5\% [12]. 
As highlighted in figure 3, the employment rate of working age population (employed people of working age in the total population of working age) was $61.4 \%$, with higher values for males employed (69.5\% versus $53.2 \%$ for women) and close by residential $(61.7 \%$ in rural areas compared to $61.3 \%$ in urban areas).

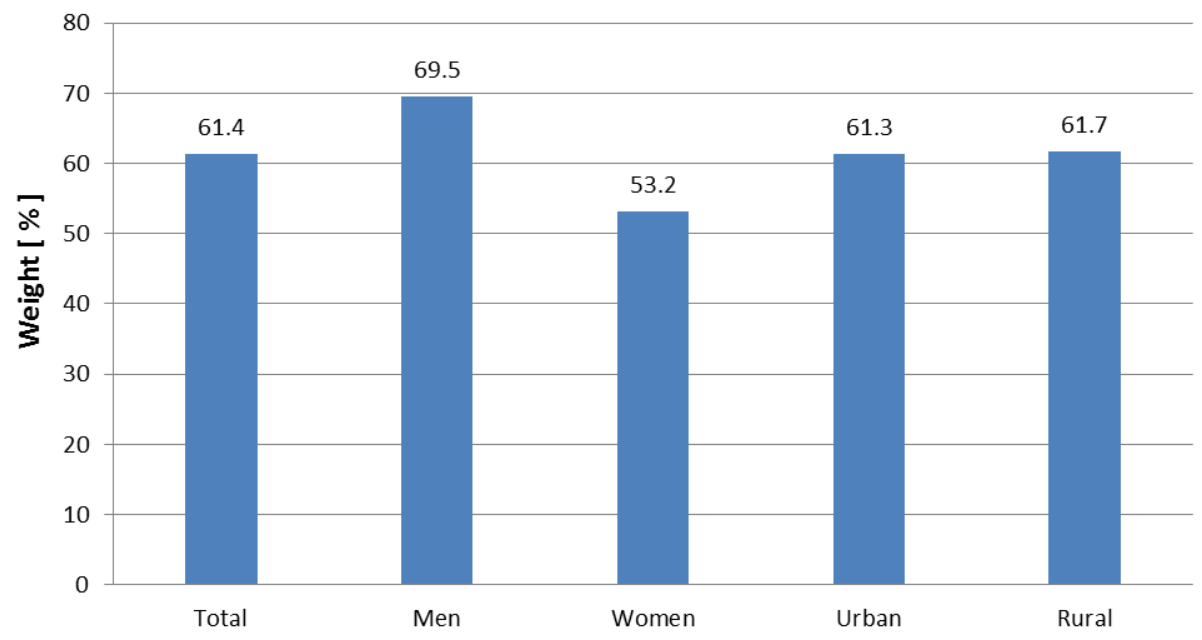

Fig. 3. The employment rate for working age people, by gender and area, 2015 [12]

Comparatively, the data from the National Institute of Statistics in the period 2014-2015 shows a decrease in the employment rate of the population aged over 15 years.

Table 1. The employment rate of the population over 15 years, on age groups in 2014-2015 [12]

\begin{tabular}{|c|c|c|c|c|c|c|c|c|}
\hline \multirow[t]{2}{*}{ Year } & \multirow{2}{*}{$\begin{array}{c}\text { Total } \\
\text { population } \\
\text { aged over } \\
15\end{array}$} & \multirow{2}{*}{$\begin{array}{l}\text { Total } \\
15-64 \\
\text { years }\end{array}$} & \multicolumn{6}{|c|}{ Age groups } \\
\hline & & & $\begin{array}{l}15-24 \\
\text { years }\end{array}$ & $\begin{array}{l}25-34 \\
\text { years }\end{array}$ & $\begin{array}{l}35-44 \\
\text { years }\end{array}$ & $\begin{array}{l}45-54 \\
\text { years }\end{array}$ & $\begin{array}{l}55-64 \\
\text { years }\end{array}$ & Over 65 \\
\hline 2014 & 51.1 & 61.0 & 22.5 & 75.1 & 80.1 & 75.6 & 43.1 & 10.8 \\
\hline 2015 & 50.8 & 61.4 & 24.5 & 74.9 & 81.1 & 75.7 & 41.1 & 8.9 \\
\hline
\end{tabular}

The evolution of staff by age provides information on the existence of a psychological balance of the enterprise (in case of uniform distribution of staff between different categories of age) or, conversely, a pronounced imbalance in the age structure that can harm psychological balance of the company (massive employment of young people hampers their opportunities for promotion).

In this context Romania has adopted the National Strategy for Employment 2014-2020 which aims to boost efforts to achieve the employment target set by Romania for 2020, namely a 70\% employment rate for the population aged 20 -64 years [13]. Fulfilling this target will contribute to achieving the goal of Romania in the European employment strategy established by 2020 , a strategy that proposes that Europe grow smart, sustainable and inclusive and to find ways to create new jobs. The strategy developed consider both national issues and challenges identified through thorough analysis of economic and social developments in the first decade of the third millennium and the challenges facing Romania in the economic crisis and recovery of the gaps compared to the EU average. In addition, the development strategy took into account strategic reference framework at European level Europe 2020 strategy and the European Employment Strategy. 


\section{Case study}

\subsection{Manufacturing company brief description}

Next, an analyzes is carried out, based on data from the past 25 years, regarding the factors that led to active aging workers who have "aged" at their jobs. The studied company has the average age of workers of 54 years and is active in the machinery industry, manufacturing, sales and repair in the field of construction machines (cranes), execution of complex steel structures. Most of the workers are older than 30 years in the company.

A considerable share relative to other companies is working after retirement in the same job. We analyzed a series of staffing resources, labor conditions, medical monitoring procedures from company archives to find good practice guide, which competed in achieving the goal of active aging.

Currently the company performs complex projects of steel structures and operates in a hall of 10,000 square meters equipped with cranes that can lift loads of up to $20 \mathrm{ft}$. and a depot equipped with gantry crane $12 \mathrm{ft}$.

The company has adapted to economic and technological change preserving human resources in the company. They installed automated welding lines; they have adopted new technologies (MIG MAG welding system) with electrode wrapped in protective gas atmosphere, it was replaced the blasting and cutting technology. Activities in the production areas held over time at temperatures of 7-8 degrees Celsius in winter and summer temperatures of 25-28 degrees Celsius. During hot periods soda was granted to workers from the own station. In the company has operated a labor union until 2008, who participated in decisions on health and safety at work.

The analysis of pollutants measurements records in 1989, 1991, 1994, 2015 show that the pollutants did not exceeded the maximum level at the workplace. Certain pollutants level decreased, other pollutants vanished through the reorganization of the company and its refurbishment [14]. There were no occupational illnesses recorded. The company recorded eight serious accidents, including one event with five victims due to human error.

\subsection{Workforce structure analysis}

The company has in his personnel structure over $70 \%$ of persons older than 30 years at the same job. Currently the company employees 72 people with an average age of 54, working as: welders (16), mechanics (22), welders (2), crane operators (9), engineers and supervisors (line management -12).

The analysis done for a staff number of 67 workers from the productive activity at company level (Figure 4) and for each job. Workers older than 50 are at the rate of $74 \%$. The percentage of $74 \%$ includes 14 retirees, former employees of the company, working as welders and mechanics. Within the company, $46 \%$ of the workers have higher seniority than 30 years.

They are specialists who trained in the vocational, secondary and postsecondary education system, existent until the 1990s. A percentage of $45 \%$ workers between 10-20 years seniority, are over 50 years, with experience gained in other companies. They employed mostly in 2004-2006. Some of them were trained in occupations they practice working with their more experienced colleagues. Only four workers are under the age of 30 years. 

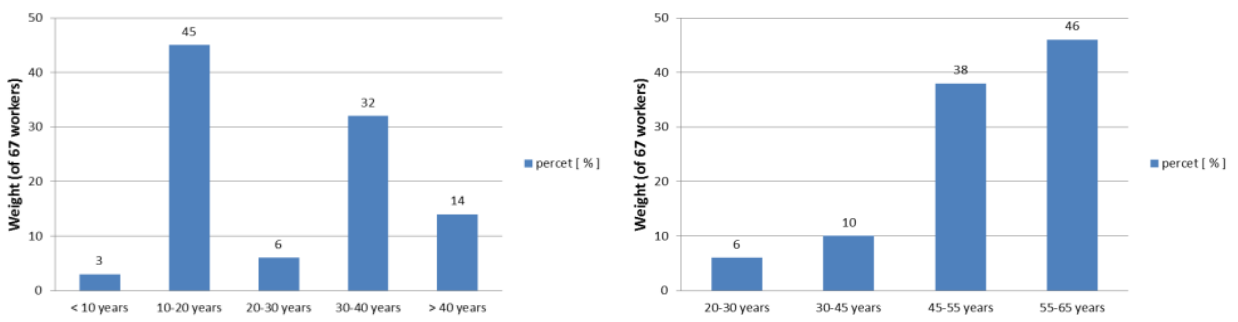

Fig. 4. Global structure of workforce: seniority category (left); age category (right)

Analysis of welders by seniority and age (figure 5) within the company shows that $88 \%$ of welders are aged over 45 years, $87 \%$ were over 20 years in seniority, of which $37 \%$ are between 30 and 40 years in seniority. The share of $50 \%$ for the $10-20$ year seniority in the company is due to refurbishment and a wave of hiring in the years 2004- 2006.
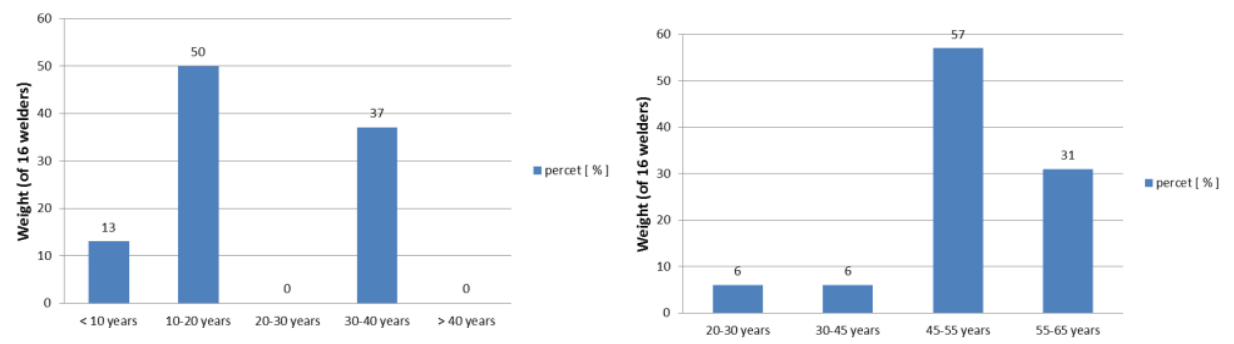

Fig. 5. Structure of welders by: seniority category (left); age category (right)

Mechanics are another category of basic productive workforce category. It observes (figure 6) the same peak at 10-20 years seniority group, related to period 2004-2006 related to the refurbishments made. Over $90 \%$ of the mechanics are older than 45 years.
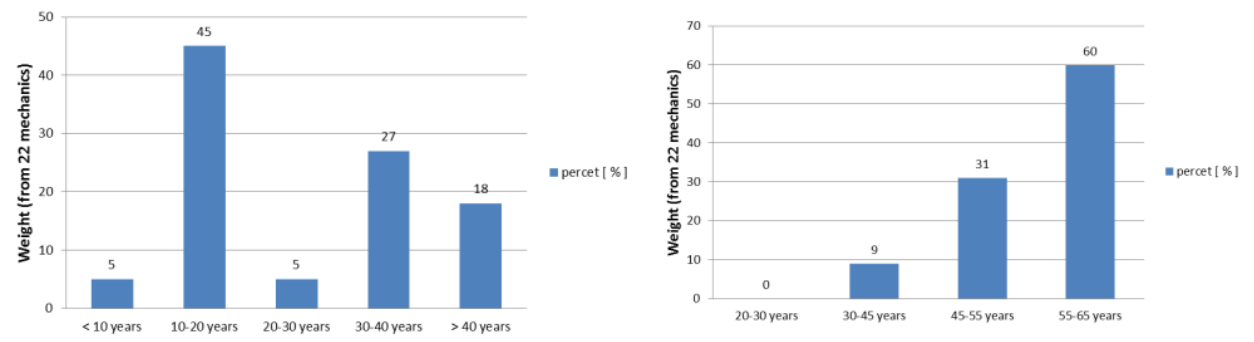

Fig. 6. Structure of mechanics by: seniority category (left); age category (right)

The crane operator is a special profession in professional careers within this company because of the special skills to acquire and keep as long as possible. Most crane operators are located in a range with 20-30 years of seniority. They participate in activities including repair, installation and operation of cranes. Teams are mixed in terms of age, since in addition to experience and rigor needed there is also required a significant level of physical activity. It is the only profession where workers distributed relatively evenly over a wide age range, comprised between 20-65 years (figure 7). 

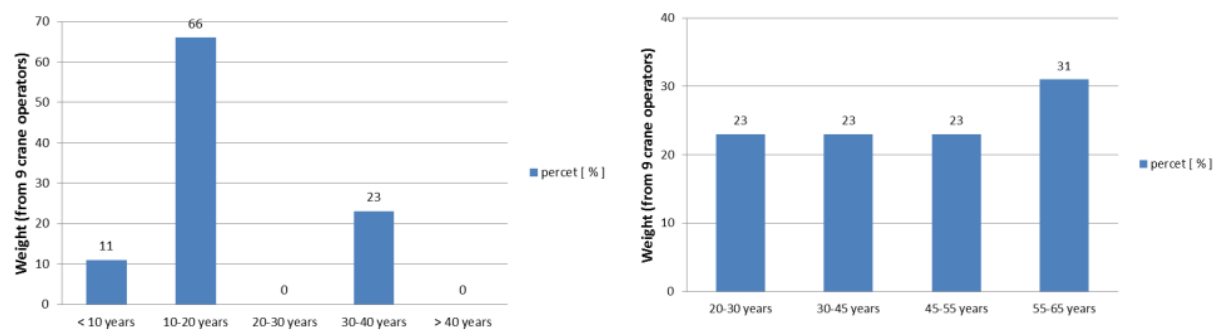

Fig. 7. Structure of crane operators by: seniority category (left); age category (right)

The company's management, on all segments of decision made mainly by people with experience of over 30 years in the company. An overwhelming majority of engineers and supervisors, over $76 \%$ of them are people who have an age over 55 years. A percentage of $34 \%$ engineers and supervisors, heads of department and directors have over 40 years in the company (figure 8).
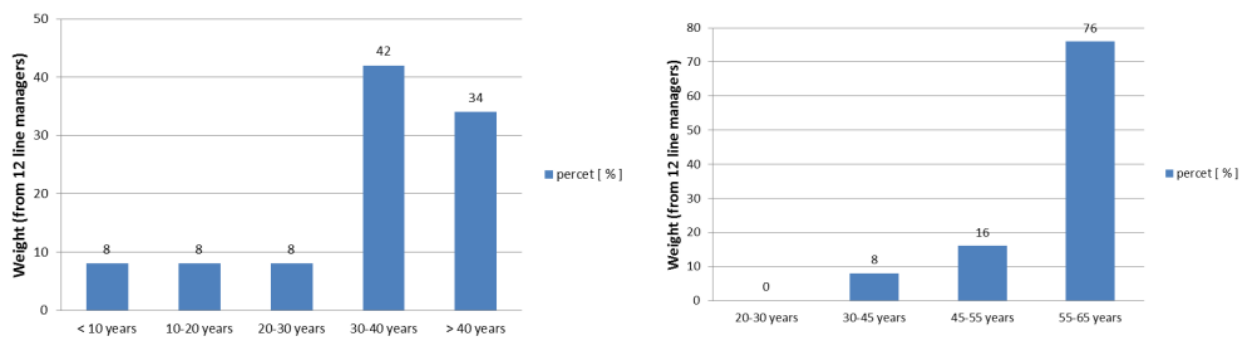

Fig. 8. Structure of line management (engineers, supervisors) by: seniority category (left); age category (right)

Occupations in which workers have in a percentage of over $80 \%$ ages over 50 years are welders, mechanics, engineers and supervisors. Gaining experience is an asset both as individual career development and as company growth by adapting legally and economically the company to the requirements of an increasingly competitive market in four occupations.

\subsection{Discussion}

The activity of people aged over 50 and those retired promoted by analyzed company policy in a complex context. The company management achieved through a core of people who have over 40 years of seniority in the company. The process of leadership ageing in this company along with the largest part of the employees has led to a relationship of loyalty unmatched by other strategies. Career development of leadership occurred in parallel with that of workers and linked to development of the company and moving together through a series of reorganizations and periods, better or worse. The general policy of the company to create premises for active aging applied throughout the years and has been beneficial for both management and workers.

Longevity of management is an important and positive factor in providing continuity of the policies and decisions taken over the years that lead to achieving long-term goals. The specific character of the company's activities required workers with high specialization and expertise. Although it is near the city of Bucharest, the labor market demand for trades exercised in the company is relatively small and casual. 
Recruitment policies of specialized personnel aged over 50 years and policies to maintain elderly and experienced personnel have adapted to the realities of the Romanian society. Concerning Romanian education system, which no longer produce the necessary specialists in all regions of the country, for all activities in the economy also adapted to the phenomenon of migration in European space of skilled workforce.

The analyzed company has developed own mentoring activities and processes. Experienced workers transmitted to their younger coworkers an information flow that helped the last ones to evolve careers in the trades they practice. The educational gap between generations can still totally complemented by mentoring in a company. Elder colleagues can submit information for career development of younger colleagues to a certain level, according their own the level of training in school. If practicing a job can increase, young workers skills, the lack of school in a particular area cannot fully compensated. An example of this would be in the company that experienced workers and having technical studies may lead a project from the execution to mounting, respectively to read and execute from the drawings and sketches, which a worker without technical learning pathways cannot do. On the other hand, younger workers have taken over the activities that required physical demands and were performing more jobs in differing workplaces.

Although in the company there were working environments with chemical pollutants, most workers have not accused major influences of the working environment on their health during their working life. The monitoring of their health state through annual checks with physicians specialists in occupational medicine revealed that just in a small percentage it was recommended the admission to work conditioned by disorders of the ear, by musculoskeletal illnesses or restrictions of work at heights. Solutions applied to compensate dysfunctions installed over time by developing other skills useful in the production process. The company not employed unskilled workers. The company has shown openness to the needs and expectations of older people. A relaxing policy installed regarding the holiday periods, rest time, recovery holidays for physical dysfunctions. Workers received days off when social obligations inherent to their age were requiring that.

This combined with the specificity of workers of this company. Most are from the suburban areas and are working off-job in farmland. Outside their working time, they are most active, working their land with their families, feeding with their own products and have a healthy lifestyle. Outdoor activity, physical labor in agriculture, a healthy lifestyle is a key factor in maintaining a healthy and active body into old age. The fact that a total of 14 pensioners are still working shows that in addition to a healthy private life, which has a main role in aging, were created in this company premises of a prolonged professional route and extensively was maintained the state of a good physical and mental health at a level that allows an active life. All management measures taken have led to the development of a competitive company, which conducted the changes imposed by economic and legislative conditions using in its core business development the human resources. Around the human resource, strategies thought and implemented to value the opportunities for change and development. Although employees get older, today the average age being 54 years, the company uses its resources effectively, which places it in the top of complex metal construction and repair and maintenance of tower cranes activities.

\section{Conclusion}

Diminishment of physical and cognitive abilities related to aging in general, does not necessarily affect performance and productivity and there is no need to treat older workers differently than young workers, as long as employers are aware that with age the physical and mental capabilities are slightly reduce. Any obstacles identified and compensated through a series of preventive measures, through education and training, and remedial action 
such as training for older workers lacking specific skills to use new technologies. Through proper management, valuable experience and skills of older workers can retained within organizations, ensuring a balance between the energy and dynamism of youth and experience of the elderly.

The manufacturing company analyzed in the case study is a perfect example of an extended professional development, having the employees' age average of 54 and half of them working for the company for more than 30 years. The company has succeeded in achieving the workforce active ageing target.

\section{References}

1. B. Rechel, E. Grundy, J.M. Robine, J. Cylus, J.P. Mackenbach, K. Knai, M. McKee, Lancet Series on Europe, 381, 9874, 1312-1322 (2013)

2. Eurostat, Archive: European population compared with world population, http://ec.europa.eu/eurostat/statistics-

explained/index.php/Archive:European_population_compared_with_world_population (2012)

3. L.I. Cioca, R.I. Moraru, G.B.Băbut, Proceedings of the $15^{\text {th }}$ International Scientific Conference „The Knowledge Based Organization”, section: Management, 2, 43-48, Land Forces Academy Sibiu, Romania (2009)

4. L.I. Cioca, R.I. Moraru, Explosion and/or fire risk assessment methodology: a common approach, structured for underground coalmine environments, 57 (1), 53 ( 2012)

5. Eurostat, Statistics Explained" European Union Labor force survey - Annual results" http://ec.europa.eu/eurostat/web/microdata/european-union-labour-force-survey, (2014)

6. Eurostat, Employment rate of people ages 20 to 64 in the EU above to $70 \%$ in 2015 , http://ec.europa.eu/eurostat/documents/2995521/7240293/3-26042016-AP-EN.pdf/2be72dc1dcbd-4beb-bad2-42c3ab792e62 (2015)

7. Eurostat, Population structure and ageing, Eurostat website, http://ec.europa.eu/eurostat/statisticsexplained/index.php/Population_structure_and_ageing (2015)

8. Health and Safety Laboratory, An update of the literature on age an employment, RR832 Research Report (2011)

9. European Parliament, Pilot project on health and safety of older workers, (2016) Accessed on 20 December 2016 at https://osha.europa.eu/en/themes/osh-management-context-ageingworkforce/ep-osh-project (2016)

10. EU-OSHA, Rehabilitation and return to work: an analysis of EU and Member State systems and programs, https://osha.europa.eu/en/tools-and-publications/publications/rehabilitation-andreturn-work-analysis-eu-and-member-state/view (2016)

11. L. Ivaşcu, L.I. Cioca, L., The $2^{\text {nd }}$ International Conference on Psychology, Management and Social Science, Psychology, Management and Social Science, Shenzhen, China, Book Series: Advances in Education Research, 49, 77-80 (2014)

12. ***, National Institute of Statistics of Romania, Press release, http://www.insse.ro/cms/sites/default/files/com_presa/com_pdf/somaj_2015r.pdf (2015)

13. Romanian Government, Government Decision no. 1071 of December 11, 2013 approving the National Strategy for Employment 2014-2020 and 2014-2020 Action Plan for implementing the National Strategy (2013)

14. V. Torretta, E.C. Rada, M. Ragazzi, Marco, et al. Waste Management 45 Special Issue: SI, pp: $152(2015)$ 